فصلنامه گياهان دارويى

doi: $10.29252 / \mathrm{jmp} .19 .75 .78$

مخغفنها: UC، كوليت زخمى؛ IBD، بيمارىهاى التهابى كولون nshahrokhi@kmu.ac.ir،nshahrokhisa@yahoo.com : نويسنده مسؤول:

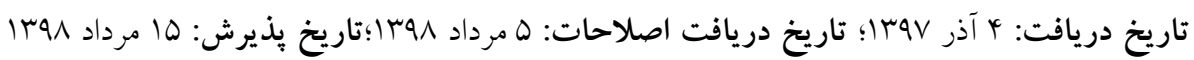
(c) 2020. Open access. This article is distributed under the terms of the Creative Commons Attribution-NonCommercial 4.0 International License (https://creativecommons.org/licenses/by-nc/4.0/) 
IL-13 (interleukin), [10] سايتو كينهاى التهابى مثل 1. [IV], TNF- $\alpha$, IL-1 [19 IL-4

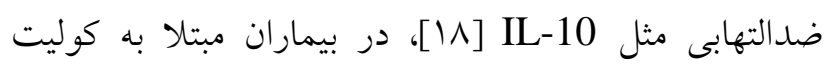
اولسراتيو در مقايسه با روده افراد سالم تغيير مى كند. IL-13

از سلولهاى LPMC (Lamina Propria Mononuclear (Cells

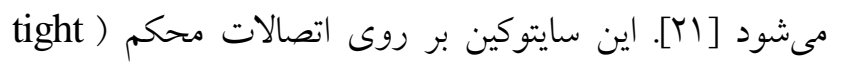

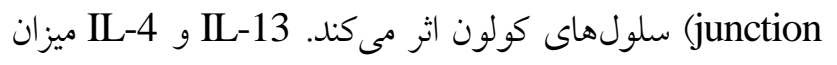

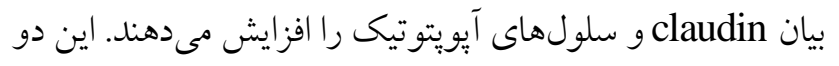
سايتوكين با يكديخر در ارتباطاند [بrان.

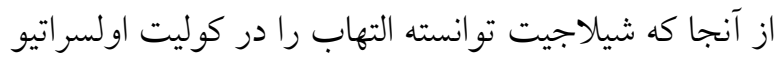
كاهش دهد [بr] در اين مطالعه سعى شده است تا مكانيسم

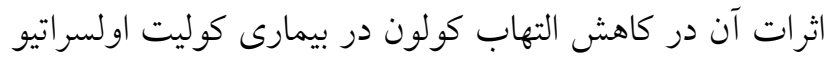

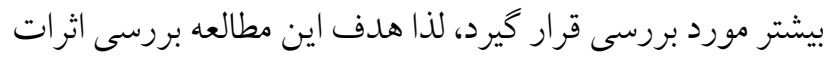

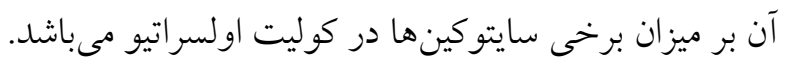

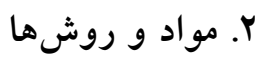
r. ا. rوش تهيه شيلاجيت

شيلاجيت مورد استفاده در اين طرح ازكوههاى منطقيه

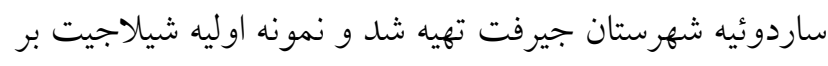

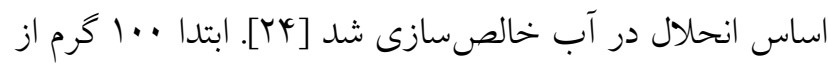

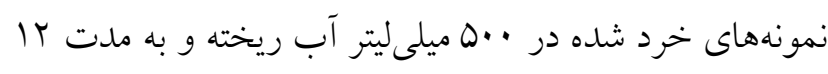

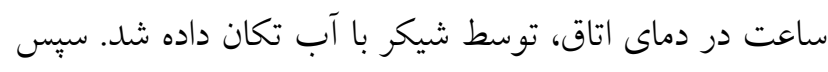

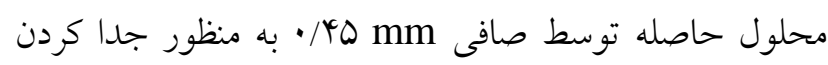

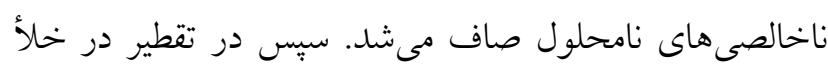

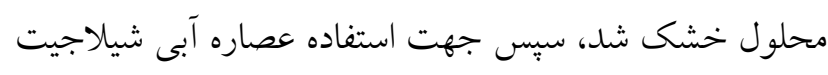

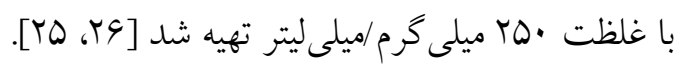

كوليت اولسراتيو (UC) يا زخم و التهاب رودهى بزرى معلى

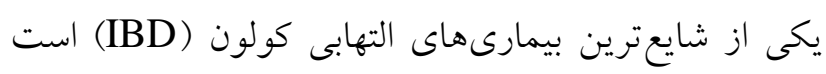

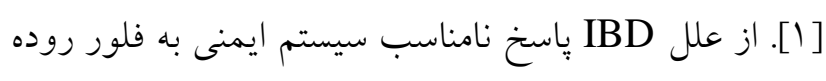

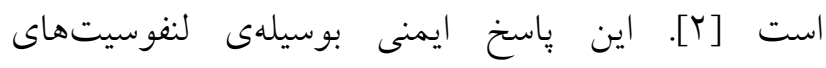

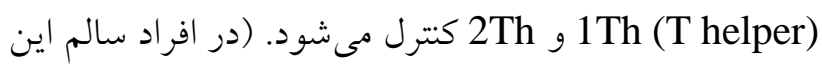
״ياسخ سركوب مىشود) [1]]. داروهاى شيميايى كه براى

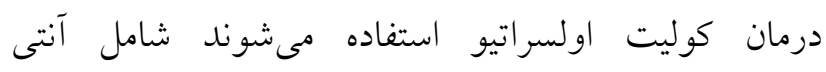
و 1 TNF (anti tumor necrosis factor) كورتيكواستروئيدها (corticosteroids) مىباشند كه تنها علائم بيمارى را كنترل مى كنتد [َّ]. اين داروها داراى

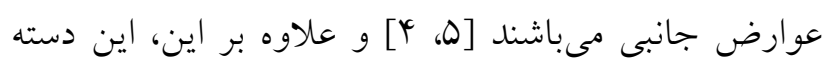

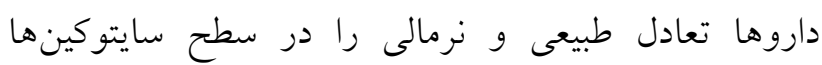
ايجاد نمى كنند. با توجه به اينكه تعادل ميان (cytokine)

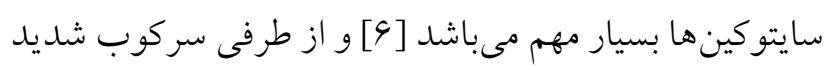

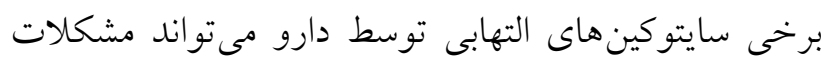

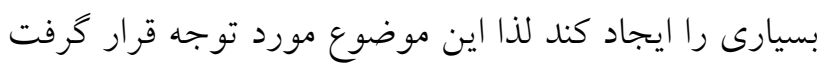

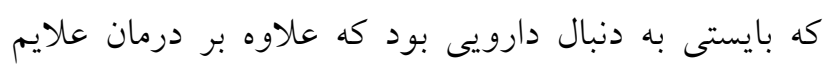

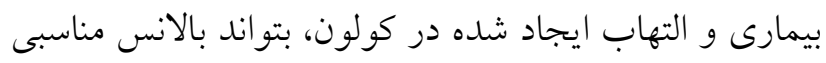

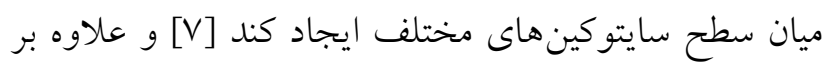

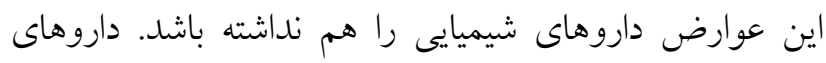

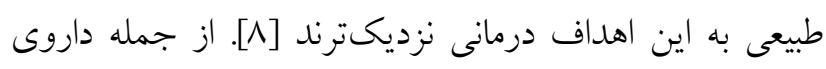

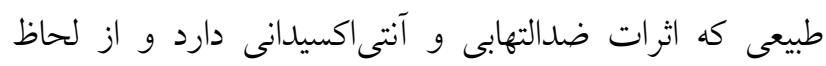

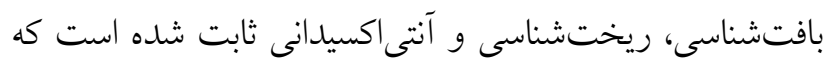

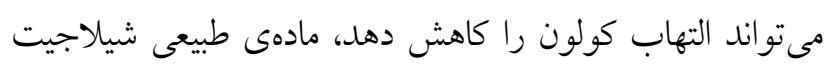
(Mumiju) است [9]. شيلاجيت (موميايى (Mujit)

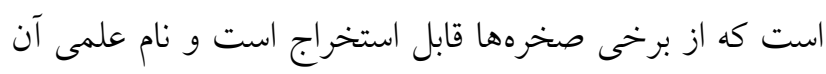

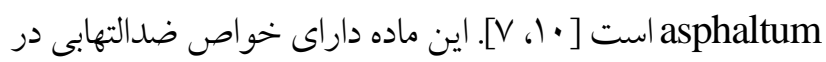

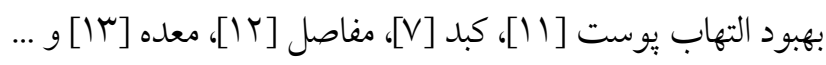

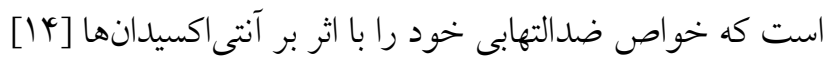

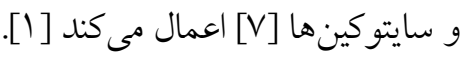


ه- كروه سولفاسالازين (sulfa) (sulfasalazine) (َ)

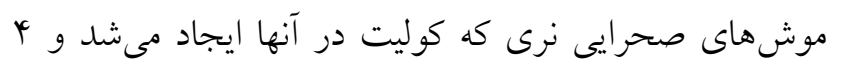

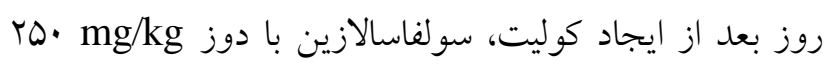

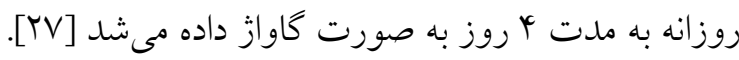

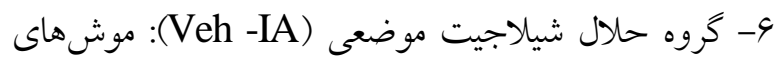

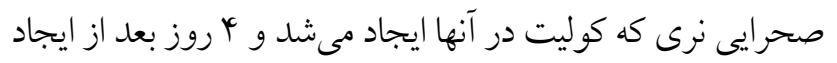

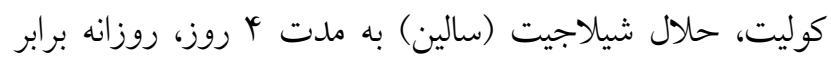

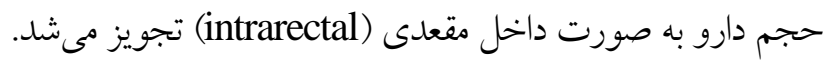

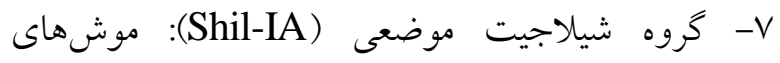

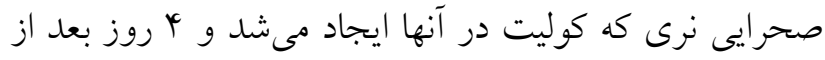

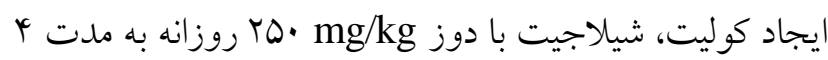

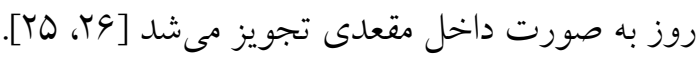

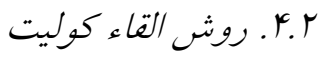

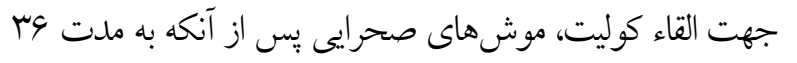

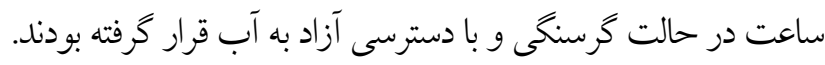

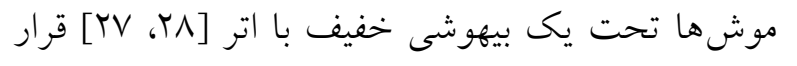

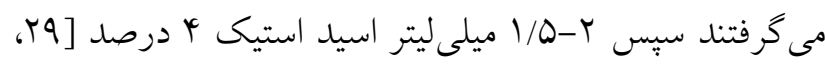

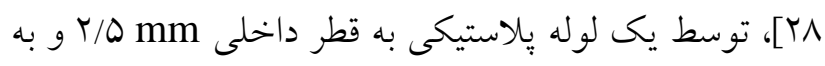

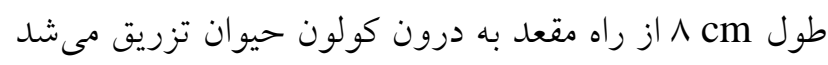

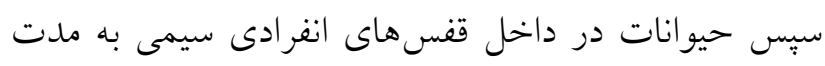

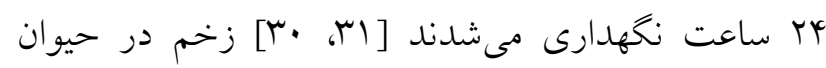

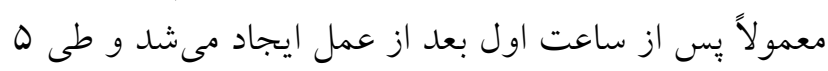

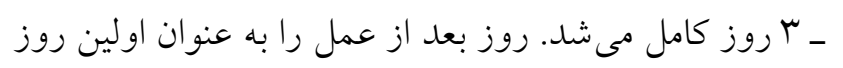

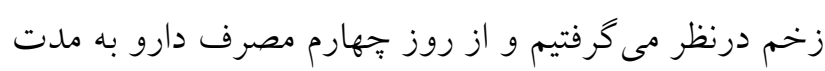

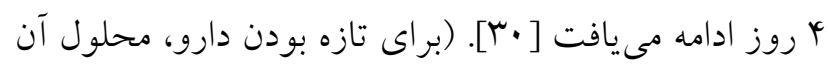
اندكى قبل از زمان تجويز تهيه مى شد.

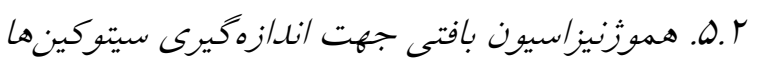

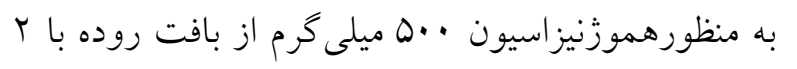

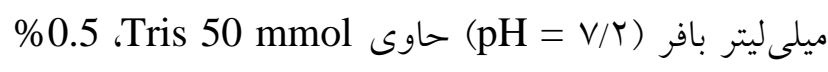

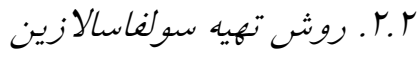

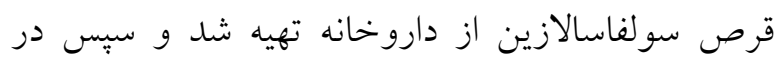

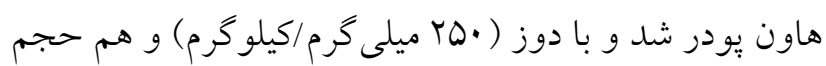

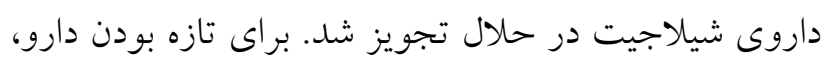

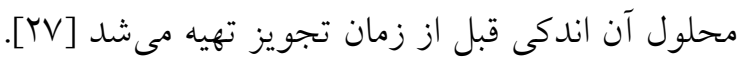

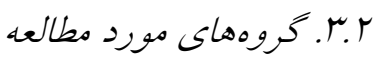

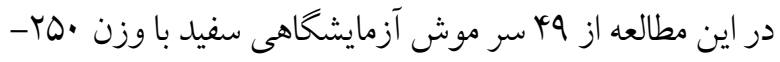

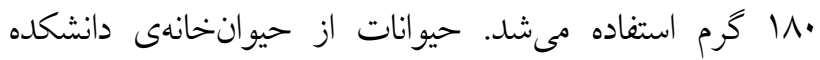

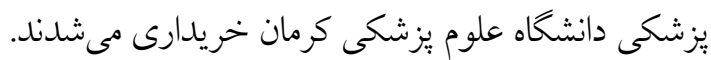

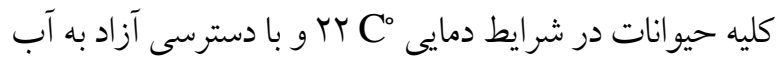

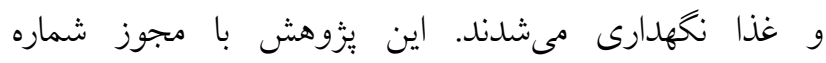

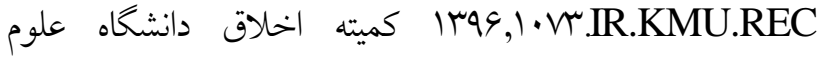
يزشكى كرمان انجام شد.

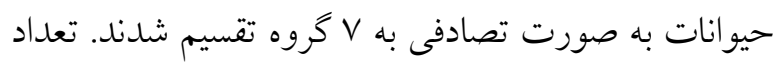

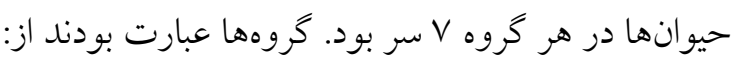

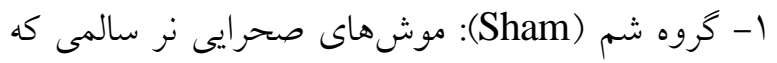

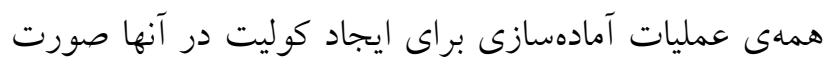

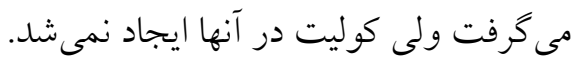

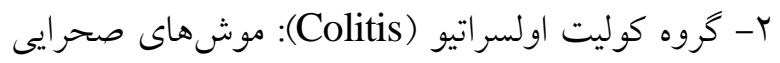

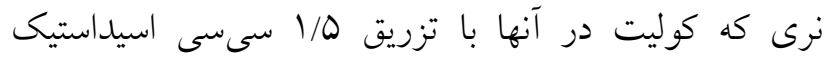
به داخل مقعد (acetic acid)

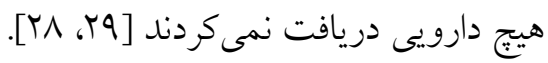

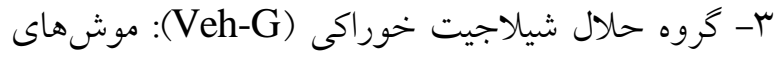

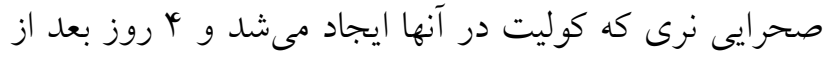

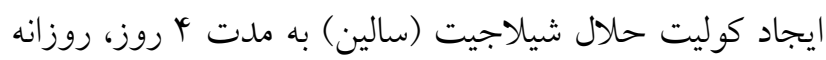
برابر حجم دارو به صورت كاواز داده مىشد.

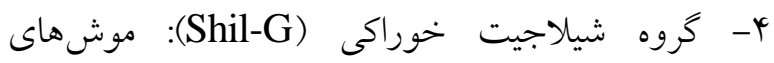

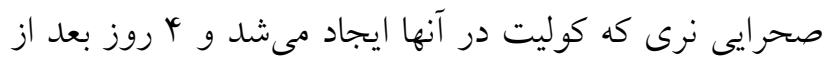
ايجاد كوليت، شيلاجيت با دوز

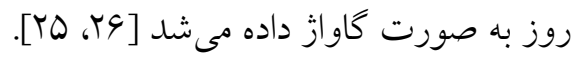


خوراكى اين مقادير را به 9. ٪

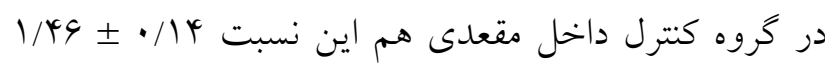

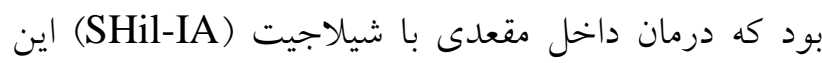

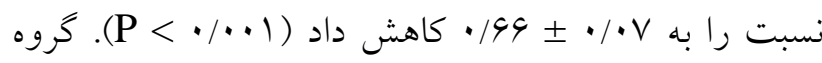

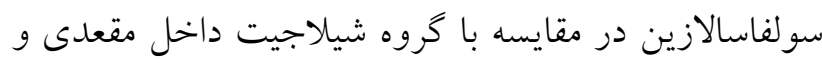

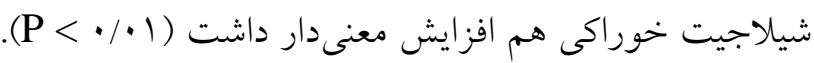

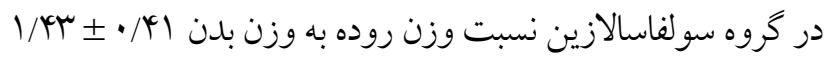

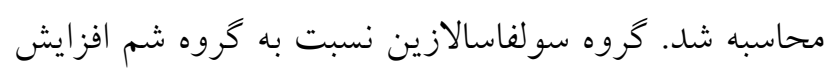

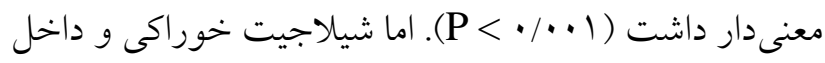
مقعدى نسبت به كروه شم تغيير معنى دارى نداشت.

r.r r.r متايسه مقادير IL-4 دركروههاى مختلف

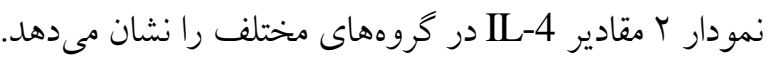

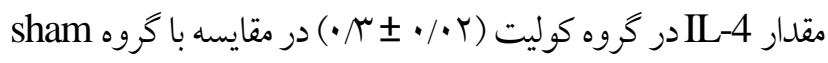

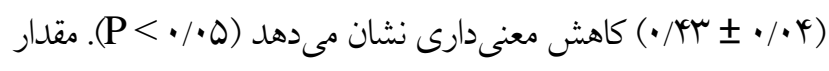
IL-4

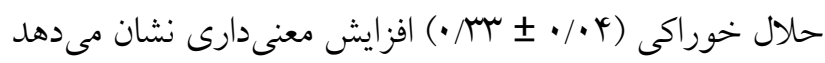

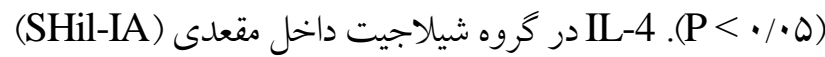

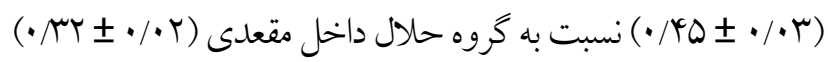

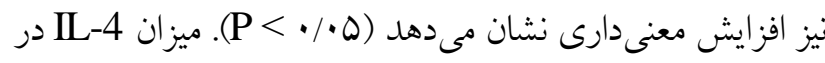

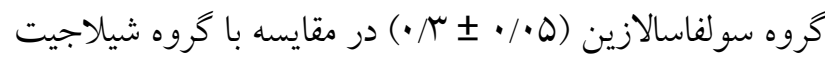

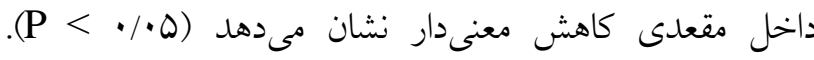
شيلاجيت خوراكى و داخل مقعدى نسبت به كروه شم تغيير

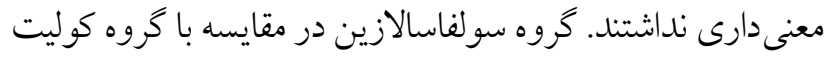
تفاوت معنى دار نداشت.

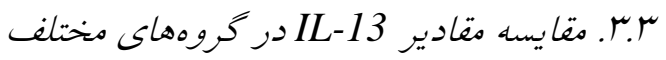

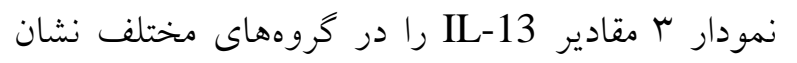

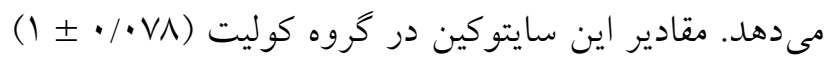

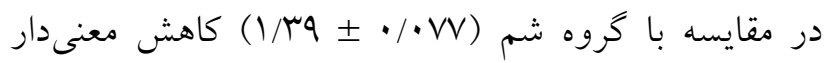

Nacl 150 mmol ،Triton 100-x يروتئاز (Roche آلمان) توسط دستخاه هموزنايزر مخلوط

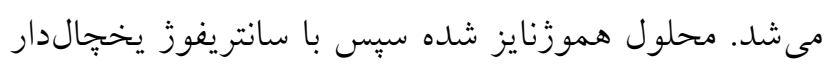

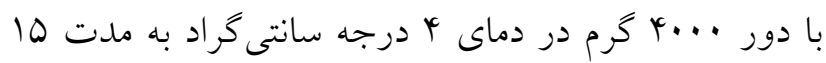

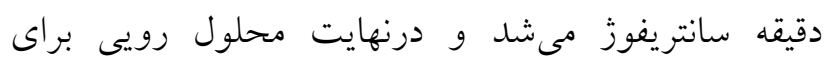

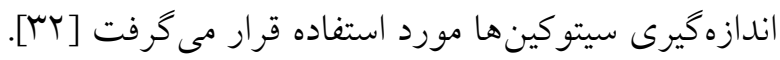

$$
\text { Y.r. 9. روش اندازهكيرى سيتوكينها }
$$

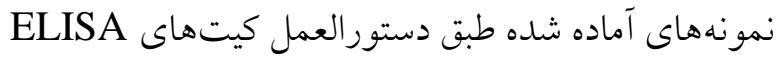
مخصوص اندازهيرى سايتو كين ها سنجش مىشدند. V.r. سا يتوكين هاى مورد بررسى IL-4, IL-13, IL-10, IL-1B, TNF-A

1.r. روش محاسبه حجم نمونه و تعداد آن

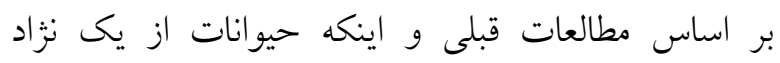

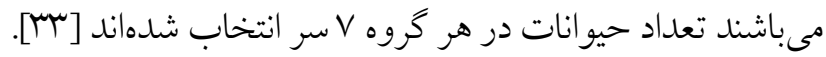
9.r. روش محاسبه و تجزيه و تحليل دادهها براى رسيدن به | اهداف طرح جهت مقايسه متغيرهاى كمى بين گروههاى مورد آزمون در

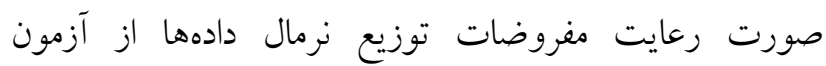
ANOVA one way

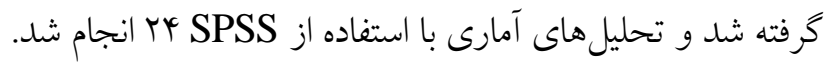

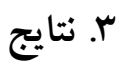
r. ا. تغييرات نسبت وزن روده به وزن بلدن دركروههاى مختلف

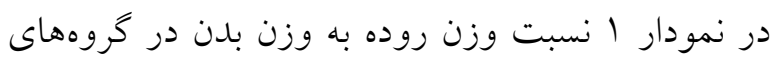

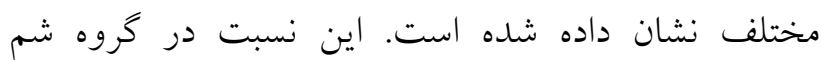

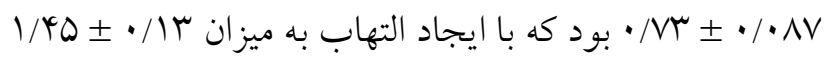

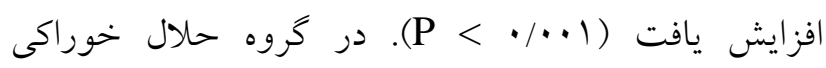
(veh-G) 


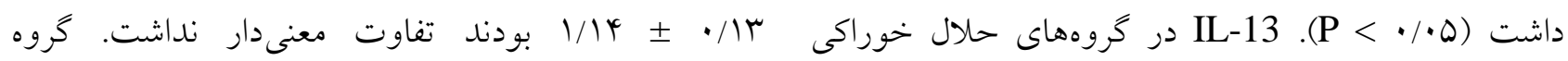

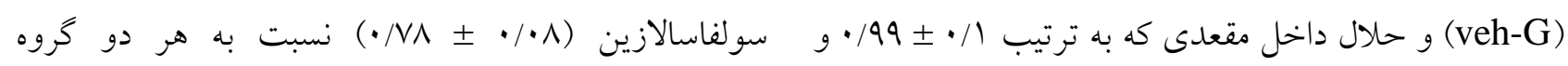

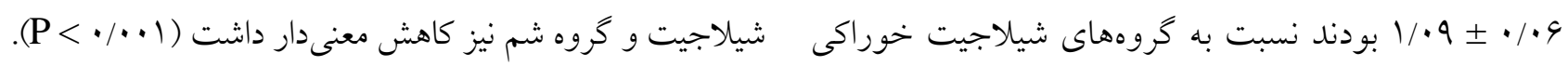

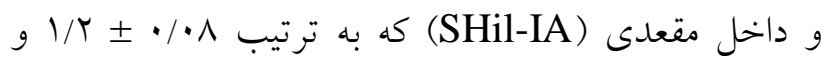

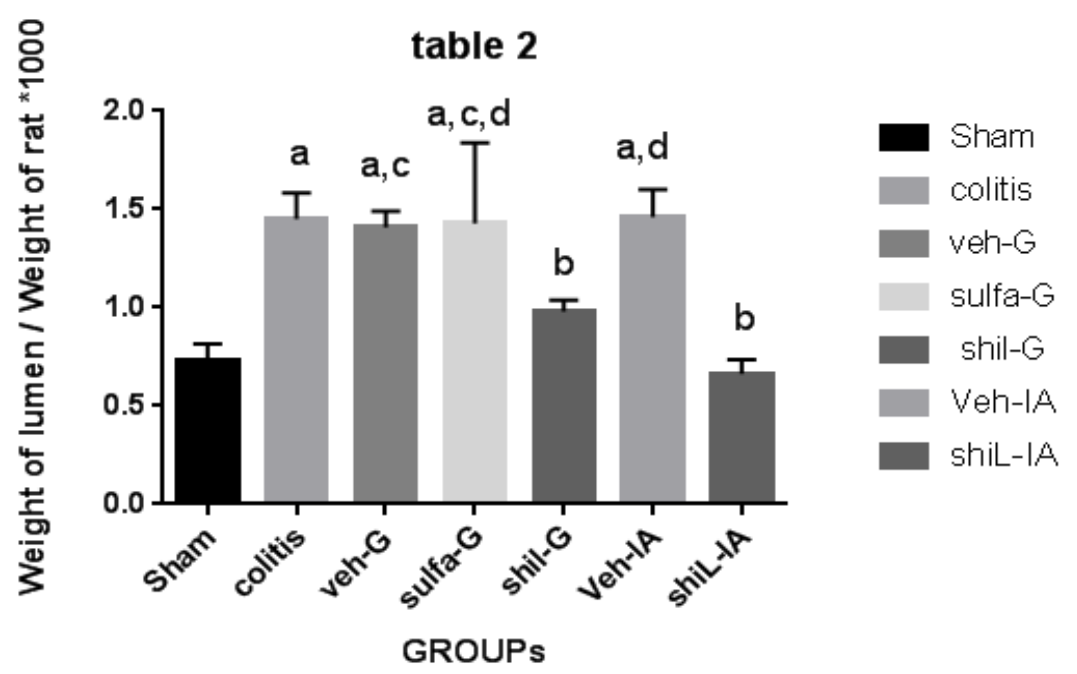

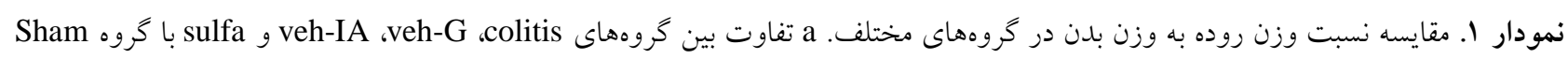

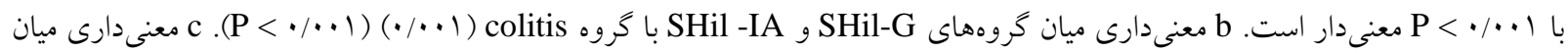

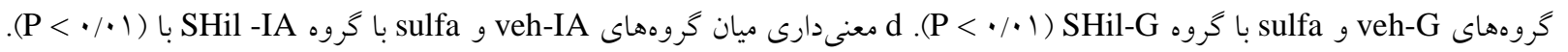

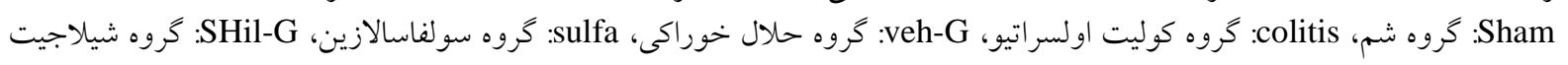

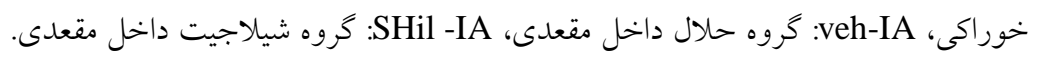

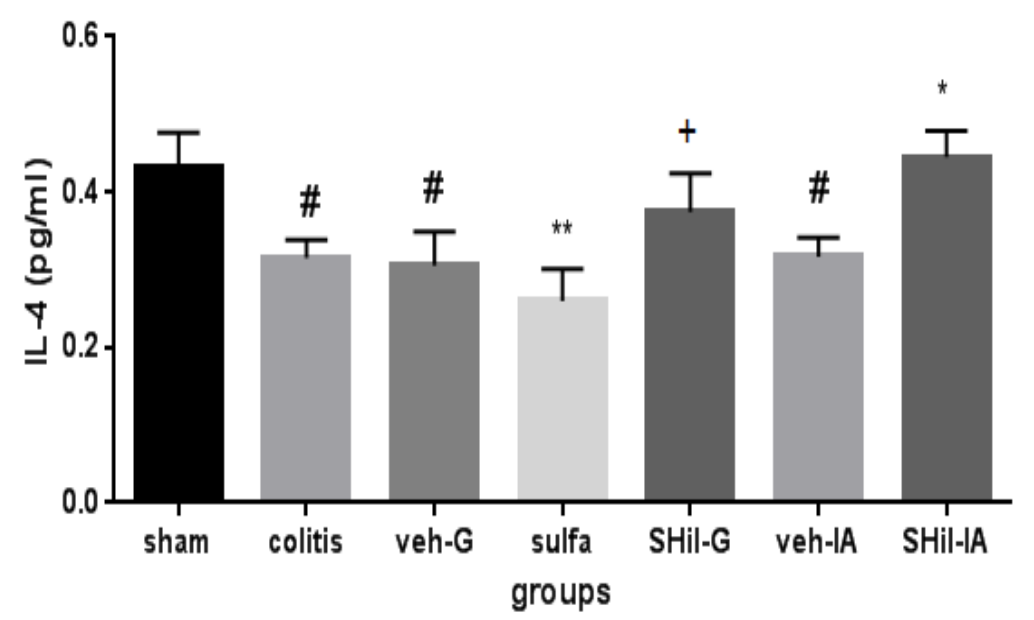

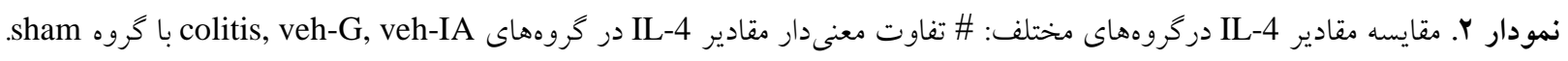

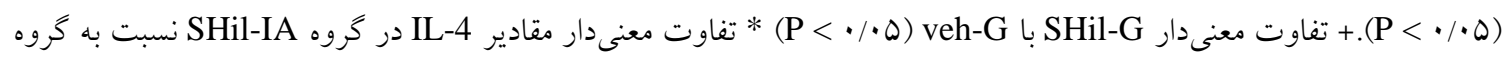

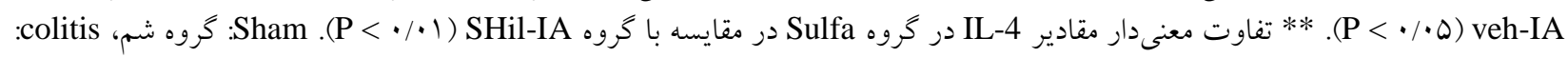

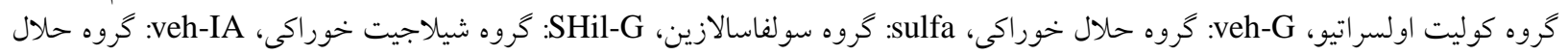
داخل مقعدى، SHil -IA: كروه شيلاجيت داخل مقعدى. 


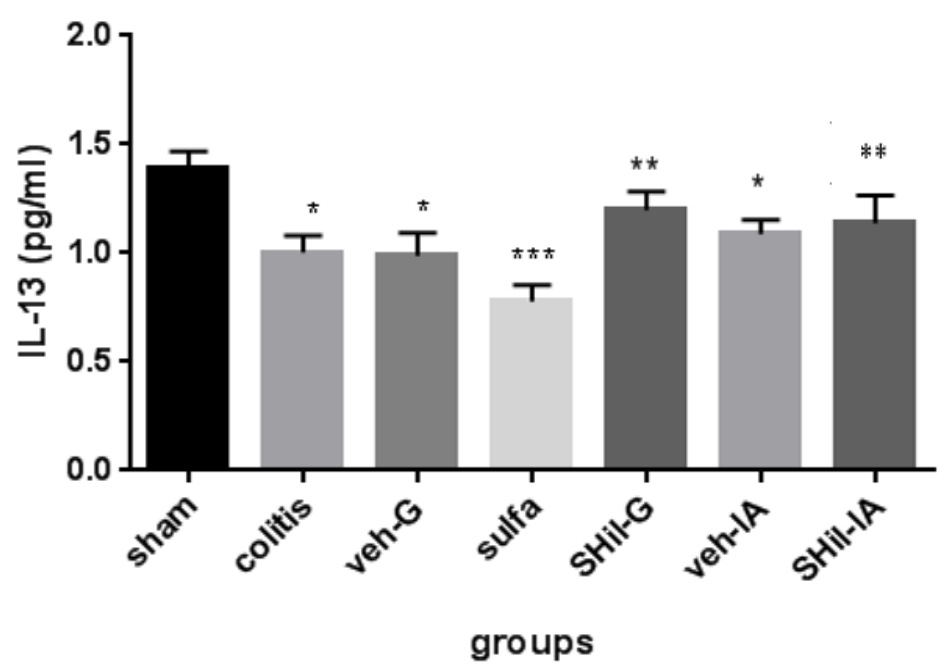

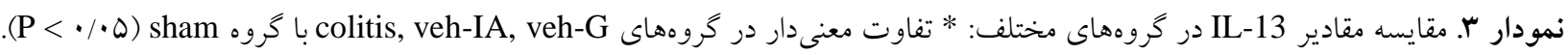

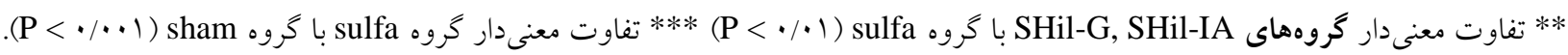

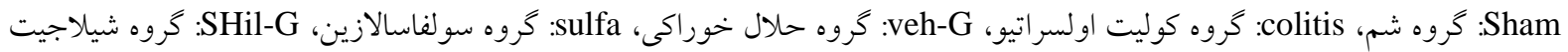

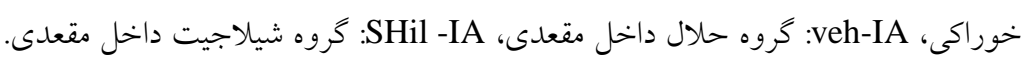

(P ) (P) مقدار اين سايتوكين در گروه شيلاجيت خوراكى (veh-G) (

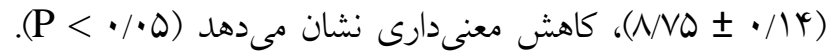
(SHil-IA) در كروه شيلاجيت داخل مقعدى IL-1 ( اختلاف معنى دار نشان نمىدهد. اما شيلاجيت داخل مقعدى نسبت

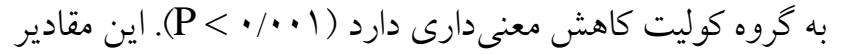

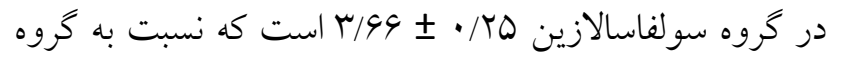

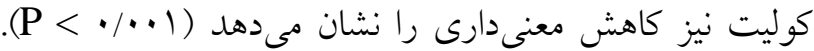

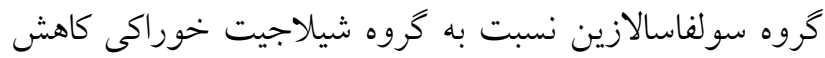

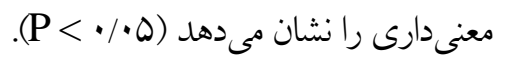

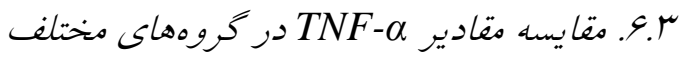
نمودار 9 مقادير TNF-

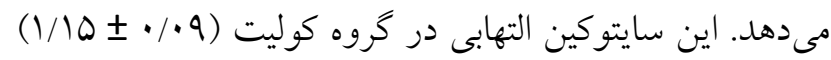

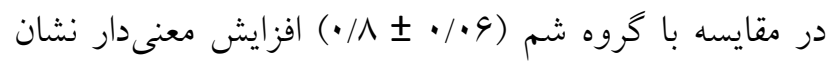

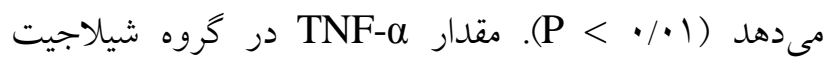

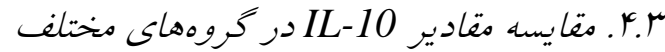

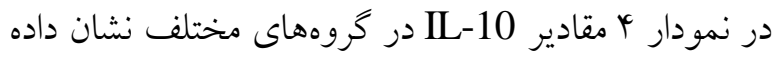

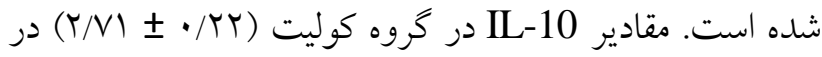
مقايسه با كروه Sham (r/DV

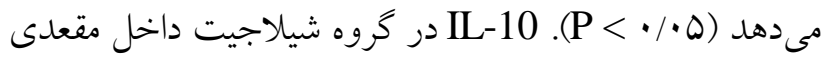

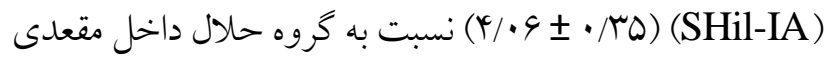

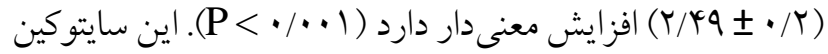

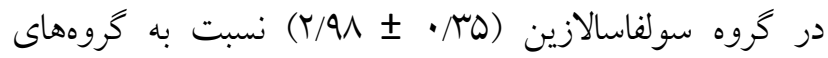

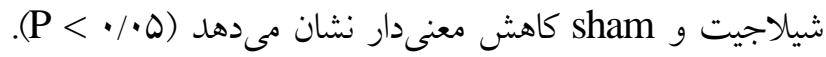

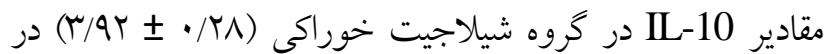

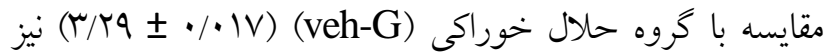

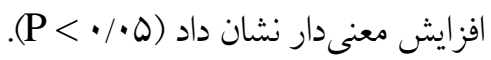

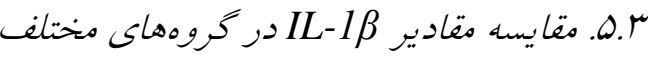
در نمودار له مقادير IL-1 در خروههاى مختلف نشان داده

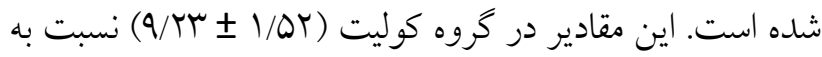

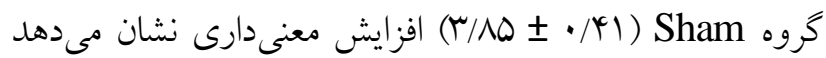




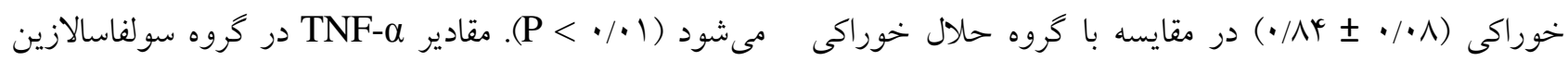

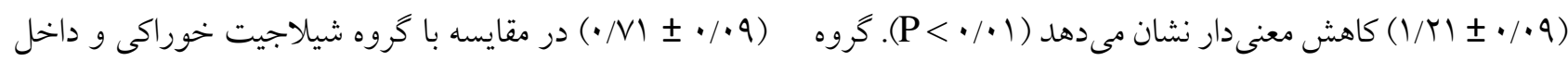

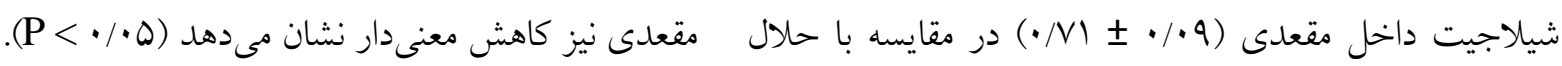

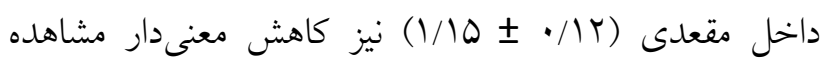

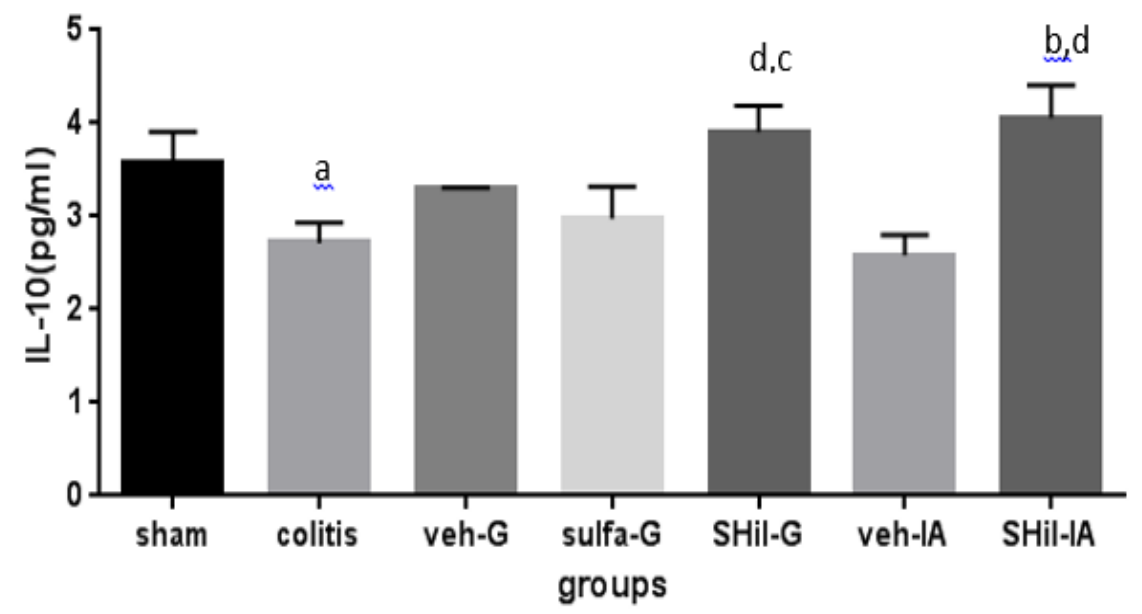

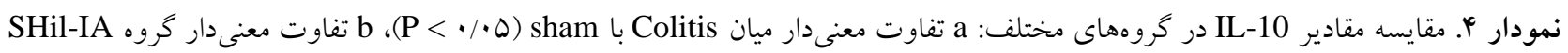

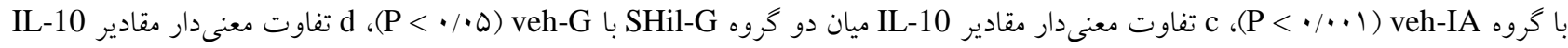

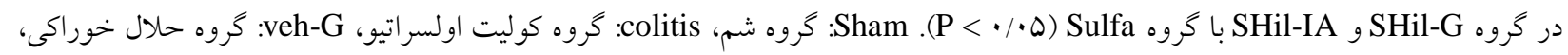
sulfa

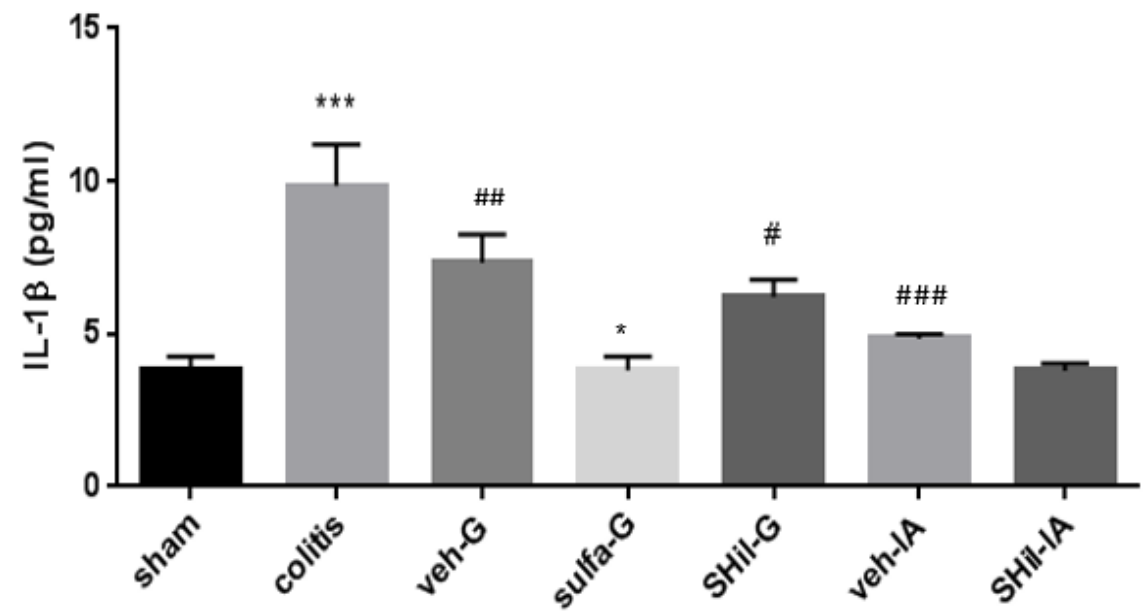

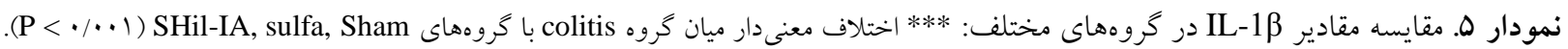

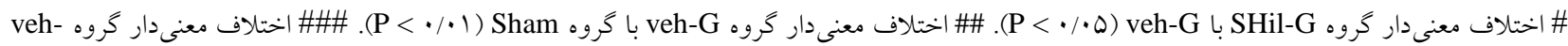
SHil-IA IA

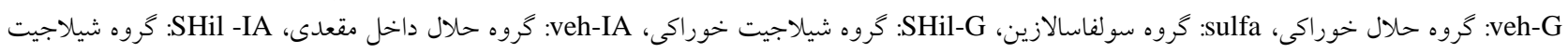
داخل مقعدى. 


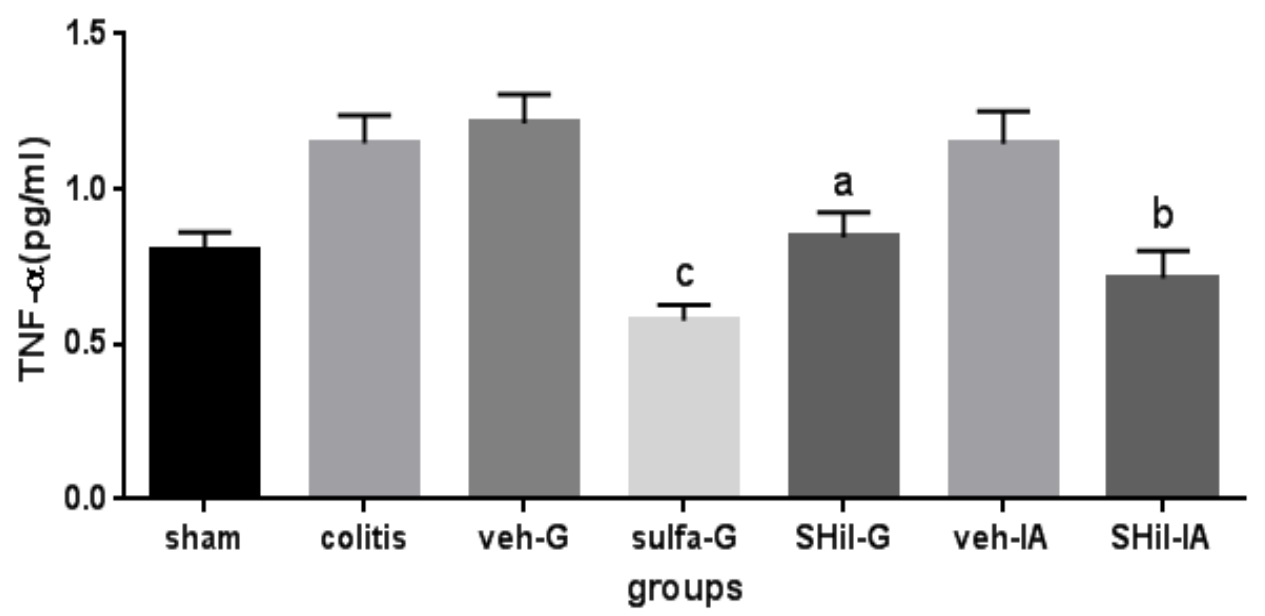

نمودار 9. مقايسه مقادير TNF-

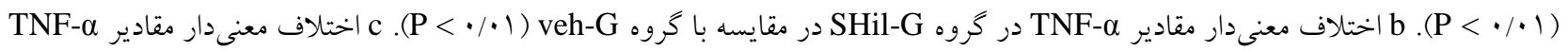

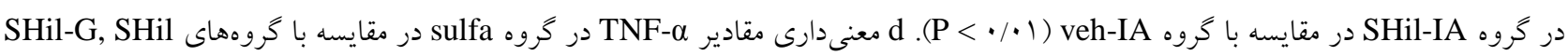

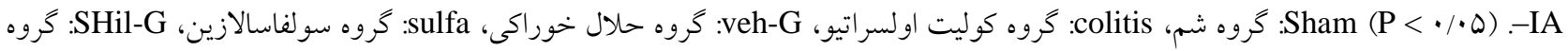

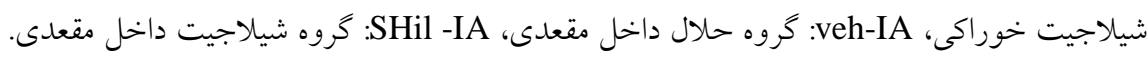

شده است كه باكترىها را مىتوان با شست و شوى روده

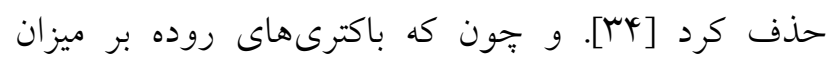

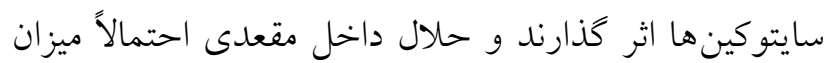

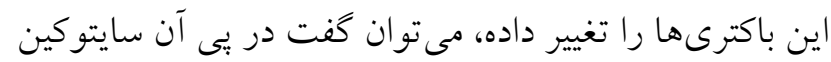

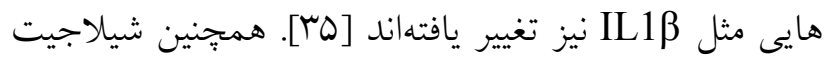

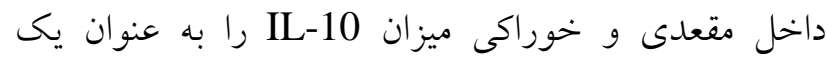

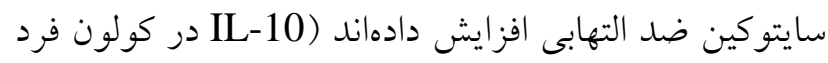

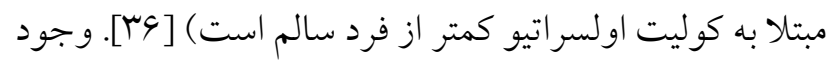

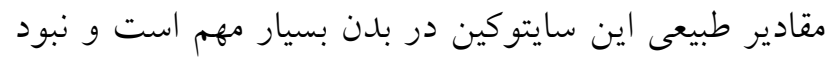

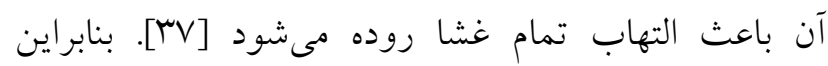
شيلاجيت با افزايش اين سايتوكين و رساندن آن به مقادير

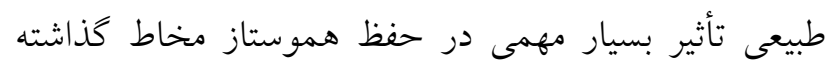

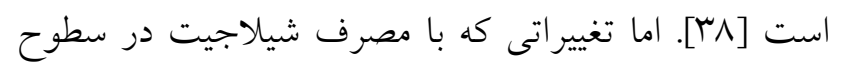
IL-13 IL-4

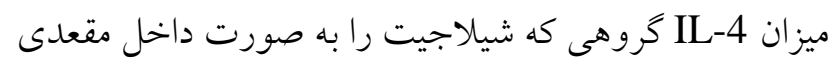

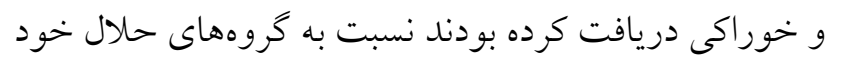

مطالعهى حاضر نشان مىدهد استفاده شيلاجيت خه به

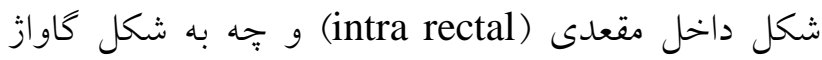

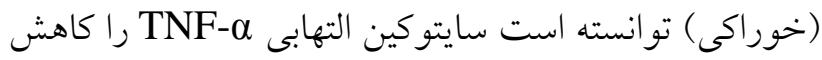
دهد. اين سايتو كين در گروه سولفاسالازين (كروه كنترل

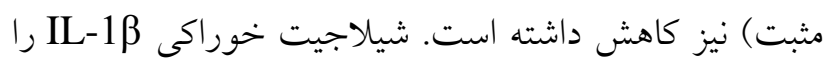
هم كاهش داده است ولى شيلاجيت داخل مقعدى در مقايسه با حلال داخل مقعدى مؤثر نبوده است، نكته قابل توجئ داده اين

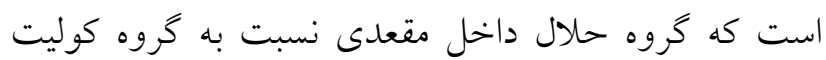

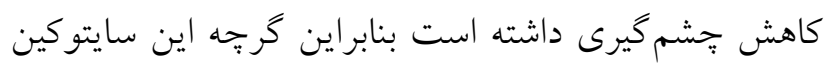

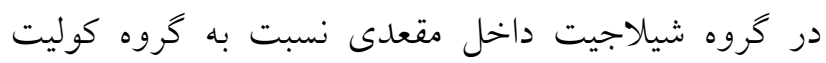

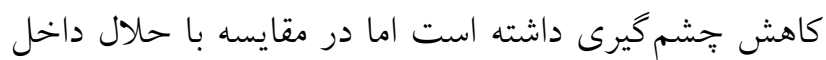
مقعدى اين كاهش ديلده نمى شود، بس بـه اين نتيجه احتمالاً

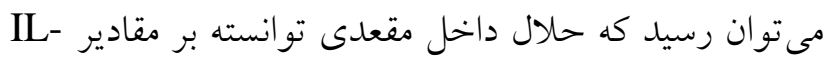

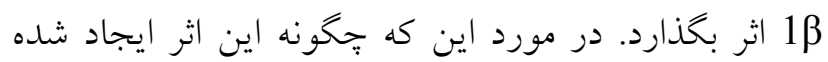

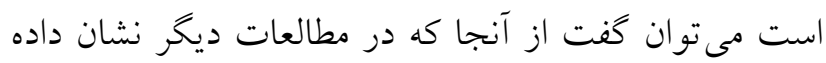


مناسبتر در سطح سايتوكينها در مقايسه با سولفاسالازين تو انسته است التهاب را بيشتر كاهش دهد. مطالعات ديخرى بر روى التهاب كبد نشان داده است كه دهن دهن

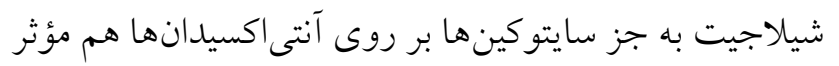

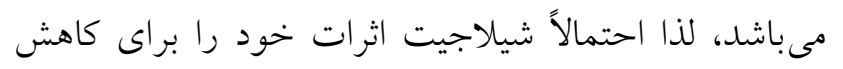

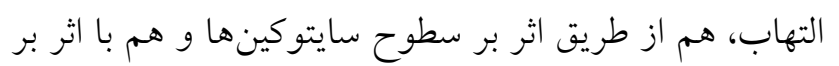

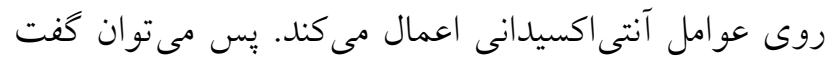

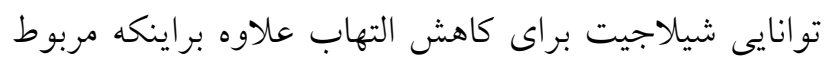

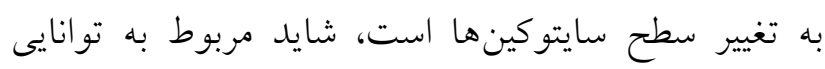
شيلاجيت در تغيير آنتى اكسيدانها نيز باشد. DSS (trinitrobenzene sulfonic acid) TNBS [rq- [ ] ]

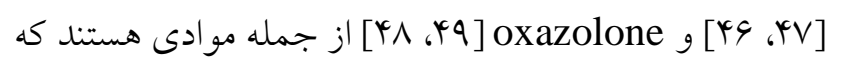

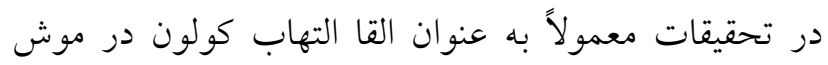

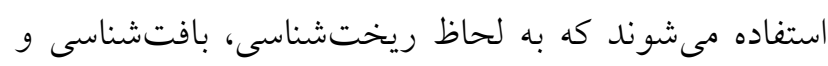

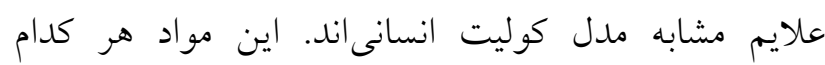

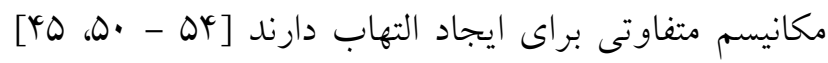
براى مثال Oxazolone با تغيير مقادير IL-13 مىتوانداد الند

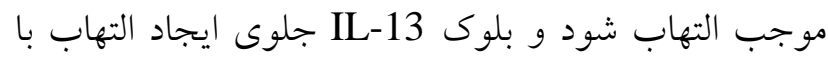

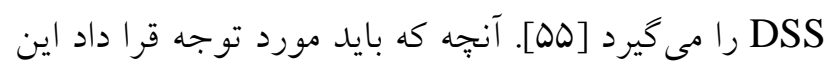

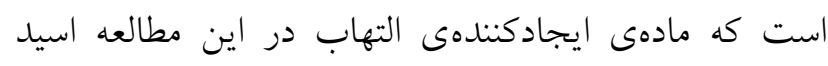

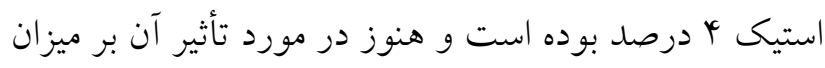

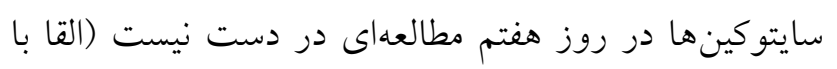

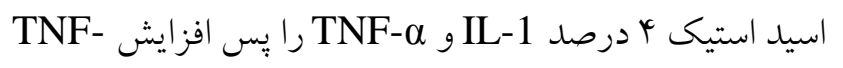

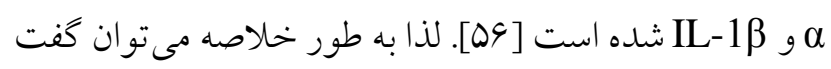
كه مصرف شيلاجيت در طى كوليت اولسراتيو با تغييرات مناسب در ميزان سايتوكينها در روند بهبود كوليت مؤثر باشد دوريت

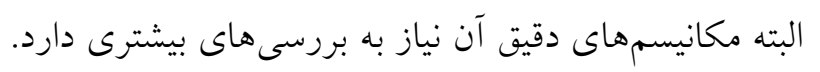

تابستان 94\$1، سال نوزدهم، شماره VQ، ص. Q1-VA
افزايش معنى دارى دارند. به هر ترتيب كرجه ميزان اين

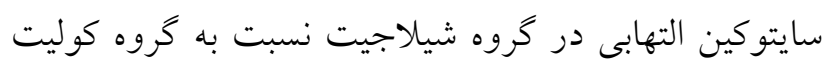

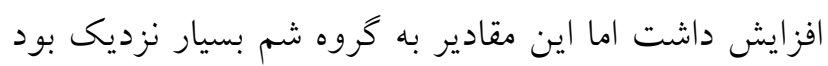

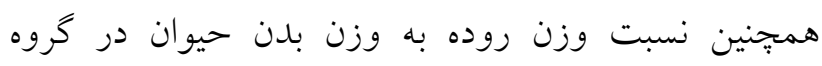

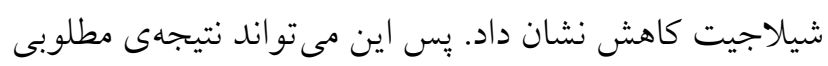

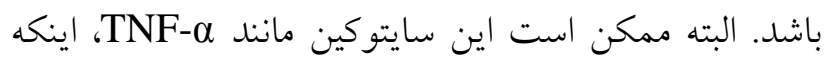

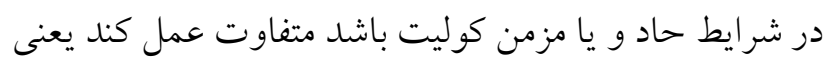

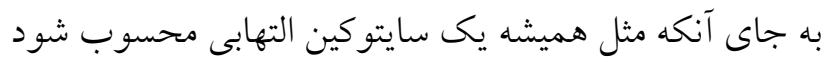

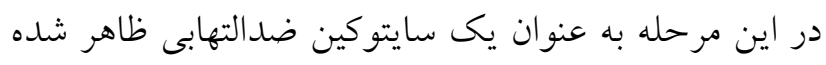

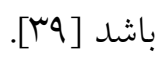
IL-13 و IL-4 با يكديخر در ارتباطاند [Tr]. در نتايج اين

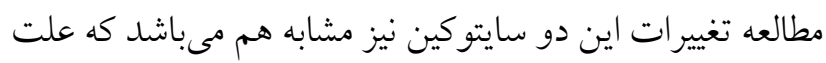
اين موضوع مىتواند همين ارتباط دو سايتوكين باشد. Brody

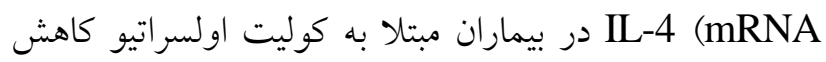

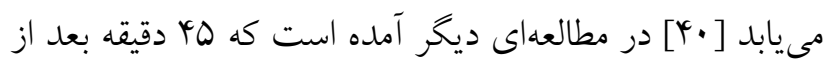

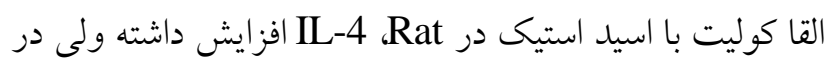

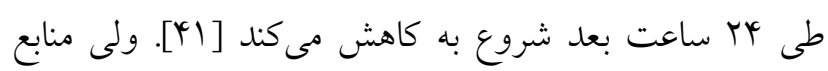

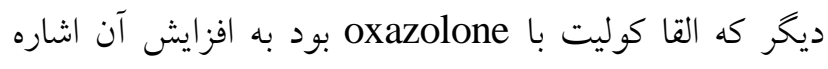

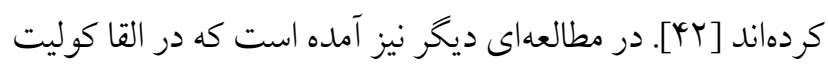

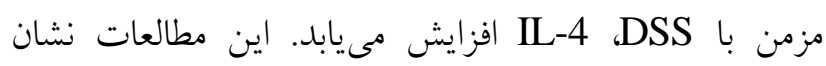

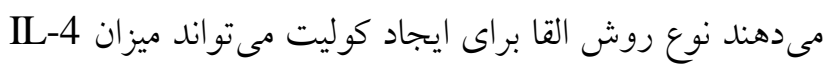

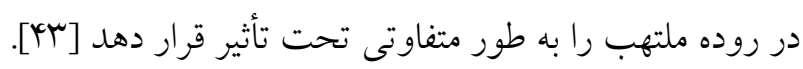

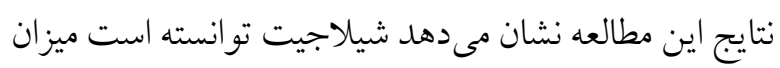
را به مقادير نرمال آنها در گروه

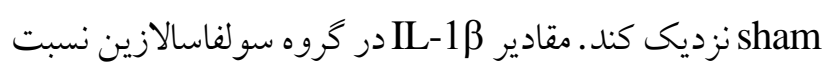
به گروه شيلاجيت به مقادير طبيعىاش در كروه شم نزديكتر

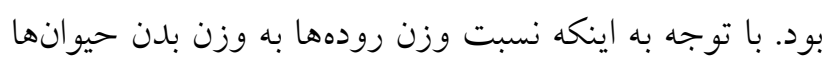
در كروههاى شيلاجيت نسبت به كروه سولفاسالازين كمتر شده

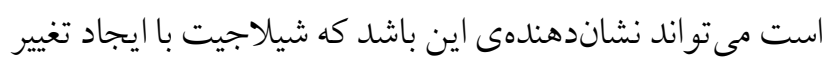




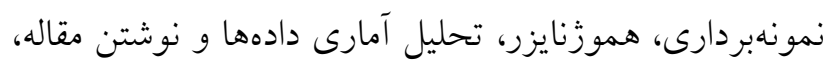

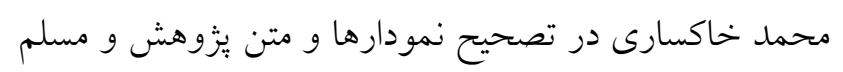

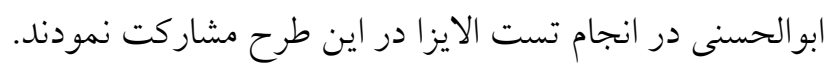

تضاد منافع

نويسندكان اعلام مى كنند كه هيج گونه تضاد منافعى وجود

ندارد.

تقدير وتشكر

با تشكر از سركار خانم دكتر نوذرى و خانم سارا شيرازيور به

خاطر راهنمايى هايى خوب و ارزنده شان.

1. Fuss IJ, Neurath M, Boirivant M, Klein JS, De

La Motte C, Strong SA and et al. Disparate CD4+ lamina propria (LP) lymphokine secretion profiles in inflammatory bowel disease. Crohn's disease LP cells manifest increased secretion of IFN-gamma, whereas ulcerative colitis LP cells manifest increased secretion of IL-5. J. Immunol. 1996; 157(3): 1261-70.

2. Sartor RB. Current concepts of the etiology and pathogenesis of ulcerative colitis and Crohn's disease. Gastroenterology Clin. North Am. 1995; 24(3): 475-507.

3. Katzung BG, Masters SB, Trevor AJ. Basic \& clinical pharmacology. 2004; 10: 1033-52.

4. Galloway JB, Hyrich KL, Mercer LK, Dixon WG, Fu B, Ustianowski AP and et al. Anti-TNF therapy is associated with an increased risk of serious infections in patients with rheumatoid arthritis especially in the first 6 months of treatment: updated results from the British Society for Rheumatology Biologics Register with special emphasis on risks in the elderly. $J$. Rheumatol. 2010; 50(1): 124-31.

5. Musa RB, Usha L, Hibbeln J and Mutlu EA. TNF inhibitors to treat ulcerative colitis in a metastatic breast cancer patient: A case report and literature review. WJG. 2014; 20(19): 5912. 6. Descamps-Latscha B, Herbelin A, Nguyen AT, Roux-Lombard P, Zingraff J, Moynot A and et al. Balance between IL-1 beta, TNF-alpha, and their specific inhibitors in chronic renal failure and maintenance dialysis. Relationships with activation markers of $\mathrm{T}$ cells, $\mathrm{B}$ cells, and monocytes. J. Immunol. 1995; 154(2): 882-92. 
7. Ghaaazi Firozsalari F, Shahrokhi N, Khaksari Hadad M, Asadikaram G and Atashbar J. Effect of Shilajit on the Levels of Pro-inflammatory and Anti-inflammation Cytokines in Hepatic Injury in Male Rats. J. Mazandaran Univ. Med. Sci. 2018; 27(159): 1-13.

8. Saxena A, Kaur K, Hegde S, Kalekhan FM, Baliga MS and Fayad R. Dietary agents and phytochemicals in the prevention and treatment of experimental ulcerative colitis. J. Tradit. Complement. Med. 2014; 4(4): 203-17.

9. Neelima S, Babu TN, Kumar MP and Kumar $\mathrm{CH}$. Effect of shilajit on acetic acid induced inflammatory bowel disease in rats. IJARMPS. 2017; 8(2): 147-50.

10. Aziz S, Khaliq S, Ghani KS, Irshad M, Green IR and Hussain H. Phytochemical Screening and Biological Studies of Shilajit (Asphaltum). International Journal of Phytomedicine 2017; 9(1): 15-9.

11. Mirza MA, Alam MN, Faiyazuddin M, Mahmood D, Bairwa R and Mustafa G. Shilajit: An ancient panacea. Int. J. Curr. Pharmaceut. Rev. Res. 2010; 1: 2-11.

12. Rege A, Juvekar P and Juvekar A. In vitro antioxidant and anti-arthritic activities of Shilajit. Int. J. Pharm. Pharm. Sci. 2012; 4(2): 650-3.

13. Shahrokhi N, Keshavarzi $Z$ and Khaksari M. Ulcer healing activity of Mumijo aqueous extract against acetic acid induced gastric ulcer in rats. J. Pharm. Bioallied. Sci. 2015; 7(1): 56.

14. Mona $S$, Neha $S$, Chhavi S, Ajay K and KM S. Asphaltum panjabinum: a new antioxidant in urolithiasis: a clinical study. JARBS. 2014; 6(2): 118-21.

15. Fuss IJ, Strober W. The role of IL-13 and NK T. cells in experimental and human ulcerative colitis. J. Mucosal. Immunology Res. 2008; 1(01): S31.

16. Berman D, Parker SM, Siegel J, Chasalow SD, Weber J, Galbraith S and et al. Blockade of cytotoxic T-lymphocyte antigen-4 by ipilimumab results in dysregulation of gastrointestinal immunity in patients with advanced melanoma. Cancer Immun. 2010; 10(1): 11.

17. Reinacker $H$, Steffen $M$, Witthoeft $T$, Pflueger I, Schreiber S, MacDermott R and et al. Enhanced secretion of tumor necrosis factoralpha, IL-6, and IL-1 beta by isolated lamina propria mononuclear cells from patients with ulcerative colitis and Crohn's disease. Clin. Exp. Immunol. 1993; 94: 174-81.

18. Li M-C and He S-H. IL-10 and its related cytokines for treatment of inflammatory bowel disease. WJG. 2004; 10(5): 620.

19. Zurawski $G$ and de Vries JE. Interleukin 13, an interleukin 4-like cytokine that acts on monocytes and B cells, but not on $\mathrm{T}$ cells. Immunology Today 1994; 15(1): 19-26.

20. de Waal Malefyt R, Figdor CG, Huijbens R, Mohan-Peterson S, Bennett B and Culpepper J. Dang W, Zurawski G and de Vries JE. Effects of IL-13 on phenotype, cytokine production, and cytotoxic function of human monocytes. Comparison with IL-4 and modulation by IFNgamma or IL-10. J. Immunol. 1993; 151(11): 6370-81. 
21. Inoue $S$, Matsumoto $T$, lida $M$, Mizuno $M$, Kuroki F, Hoshika K and et al. Characterization of cytokine expression in the rectal mucosa of ulcerative colitis: correlation with disease activity. AJG. 1999; 94(9): 2441-6.

22. Heller F, Florian P, Bojarski C, Richter J, Christ M, Hillenbrand B and et al. Interleukin-13 is the key effector Th2 cytokine in ulcerative colitis that affects epithelial tight junctions, apoptosis, and cell restitution. Gastroenterol. 2005; 129(2): 550-64.

23. Shahrokhi N, Asadikaram GH and Amirafzali F. Protective effect of Mumiju against acetic acid-induced ulcerative colitis in rats. AJP. 2018; 8(5): 457.

24. Kumar V, Abbas AK, Fausto $\mathrm{N}$ and Aster JC. Robbins and Cotran Pathologic Basis of Disease, Professional Edition E-Book: Elsevier Health Sciences, 2014.

25. Ran $\mathrm{ZH}$, Chen $\mathrm{C}$, Xiao SD. Epigallocatechin-3-gallate ameliorates rats colitis induced by acetic acid. Biomed Pharmacothe. 2008; 62(3): 189-96.

26. Phaechamud T, Charoenteeraboon J, Wetwitayaklung P, Limmatvapirat $\mathrm{C}$ and Srichan T. Some Biological Activities and Safety of Mineral Pitch. SUSTJ. 2008; 2(2): 7-17.

27. Ran ZH, Chen $\mathrm{C}$ and Xiao SD. Epigallocatechin-3-gallate ameliorates rats colitis induced by acetic acid. Biomed. Pharmacothe. 2008; 62(3): 189-96.

28. Noa M, Más R and Carbajal D. Effect of D002 on acetic acid-induced colitis in rats at single and repeated doses. Pharmacol. Res. 2000; 41(4): 391-5.

تابستان 99 ا، سال نوزدهم، شماره VQ، ص. 91-VA

29. MacPherson $B$ and Pfeiffer $C$. Experimental production of diffuse colitis in rats. Digestion. 1978; 17(2): 135-50.

30. Fabia R, Willen R, Ar'Rajab A, Andersson $\mathrm{R}$, Ahren B and Bengmark S. Acetic acidinduced colitis in the rat: a reproducible experimental model for acute ulcerative colitis. Eur. Sur. Res. 1992; 24(4): 211-25.

31. Hagar HH, El Medany A, El Eter E and Arafa M. Ameliorative effect of pyrrolidinedithiocarbamate on acetic acidinduced colitis in rats. Eur. J. Pharmacol. 2007; 554(1): 69-77.

32. McKelvey-Martin V, Green M, Schmezer P, Pool-Zobel B, De Meo M and Collins A. The single cell gel electrophoresis assay (comet assay): a European review. Mutat. Res. 1993; 288(1): 47-63.

33. Chern CM, Liao JF, Wang YH and Shen YC. Melatonin ameliorates neural function by promoting endogenous neurogenesis through MT2 melatonin receptor in ischemic stroke mice. Free Rad. Biol. Med. 2012; 52(9): 16341647.

34. Jung HC, Eckmann L, Yang S-k, Panja A, Fierer J, Morzycka-Wroblewska E and et al. A distinct array of proinflammatory cytokines is expressed in human colon epithelial cells in response to bacterial invasion. JCI. 1995; 95(1): 55-65.

35. Abreu MT. Toll-like receptor signalling in the intestinal epithelium: how bacterial recognition shapes intestinal function. Nat. Rev. Immunol. 2010; 10(2): 131.

36. Lih-Brody L, Powell SR, Collier KP, Reddy GM, Cerchia R, Kahn E and et al. 
Increased oxidative stress and decreased antioxidant defenses in mucosa of inflammatory bowel disease DIGEST. 1996; 41(10): 2078-86. 37. Berg DJ, Davidson N, Kühn R, Müller W, Menon S, Holland G and et al. Enterocolitis and colon cancer in interleukin-10-deficient mice are associated with aberrant cytokine production and CD4 (+) TH1-like responses. JCI. 1996; 98(4): 1010-20.

38. Zigmond E, Bernshtein B, Friedlander G, Walker CR, Yona S, Kim K-W and et al. Macrophage-restricted interleukin-10 receptor deficiency, but not IL-10 deficiency, causes severe spontaneous colitis. Immunity 2014; 40(5): 720-33.

39. Kojouharoff G, Hans W, Obermeier F, MA NNEL D, Andus T, SCHO LMERICH J and et al. Neutralization of tumour necrosis factor (TNF) but not of IL-1 reduces inflammation in chronic dextran sulphate sodium-induced colitis in mice. J. Clin. Exp. Immunol. 1997; 107(2): 353-8.

40. West G, Matsuura T, Levine A, Klein J and Fiocchi C. Interleukin 4 in inflammatory bowel disease and mucosal immune reactivity. Gastroenterol. 1996; 110(6): 1683-95.

41. Bertevello PL, Logullo ÂF, Nonogaki S, Campos FM, Chiferi V, Alves CC and et al. Immunohistochemical assessment of mucosal cytokine profile in acetic acid experimental colitis. Clinics 2005; 60(4): 277-86.

42. Boirivant M, Fuss IJ, Chu A and Strober W. Oxazolone colitis: a murine model of $\mathrm{T}$ helper cell type 2 colitis treatable with antibodies to interleukin 4. JEM. 1998; 188(10): 1929-39.
43. Rees V. Chronic experimental colitis induced by dextran sulphate sodium (DSS) is characterized by Th1 and Th2 cytokines. Clin. Exp. Immunol. 1998; 114(3): 385-91.

44. Cheah KY, Bastian SE, Acott TM, Abimosleh SM, Lymn KA and Howarth GS. Grape seed extract reduces the severity of selected disease markers in the proximal colon of dextran sulphate sodium-induced colitis in rats. Dig. Dis. Sci. 2013; 58(4): 970-7.

45. Dharmani $P$, Leung $P$ and Chadee $K$. Tumor necrosis factor- $\alpha$ and Muc2 mucin play major roles in disease onset and progression in dextran sodium sulphate-induced colitis. PloS One 2011; 6(9): e25058.

46. da Silva MS, Sánchez-Fidalgo $S$, Talero E, Cárdeno A, da Silva MA, Villegas W and et al. Anti-inflammatory intestinal activity of Abarema cochliacarpos (Gomes) Barneby \& Grimes in TNBS colitis model. $J$. Ethnopharmacol. 2010; 128(2): 467-75.

47. De Almeida ABA, Sanchez-Hidalgo M, Martín AR, Luiz-Ferreira A, Trigo JR, Vilegas $\mathrm{W}$ and et al. Anti-inflammatory intestinal activity of Arctium lappa L. (Asteraceae) in TNBS colitis model. J. Ethnopharmacol. 2013; 146(1): 300-10.

48. Ding TT. Therapeutic effects of Clostridium butyricum on experimental colitis induced by oxazolone in rats. WJG. 2009; 15: 007.

49. Yang J, Zhao J, Nakaguchi $T$ and Gregersen H. Biomechanical changes in oxazoloneinduced colitis in BALB/C mice. $J$. Biomechanics 2009; 42(7): 811-7. 
50. Morris GP, Beck PL, Herridge MS, Depew WT, Szewczuk MR and Wallace JL. Hapteninduced model of chronic inflammation and ulceration in the rat colon. Gastroenterol. 1989; 96(2): 795-803.

51. Isik F, Akbay $T T$, Yarat $A$, Genc $Z$, Pisiriciler R, Caliskan-Ak E and et al. Protective effects of black cumin (Nigella sativa) oil on TNBS-induced experimental colitis in rats. Dig. Dis. Sci. 2011; 56(3): 721-30.

52. Elson CO, Sartor RB, Tennyson GS and Riddell RH. Experimental models of inflammatory bowel disease. Gastroenterol. 1995; 109(4): 1344-67.

53. Yu Q, Zhu S, Zhou R, Yi F, Bing Y, Huang $S$ and et al. Effects of sinomenine on the expression of microRNA-155 in 2, 4, 6trinitrobenzenesulfonic acid-induced colitis in mice. PloS One. 2013; 8(9): e73757.

54. Ni J, Chen S and Hollander D. Effects of dextran sulphate sodium on intestinal epithelial cells and intestinal lymphocytes. Gut. 1996;
39(2): 234-41.

55. Heller F, Fuss IJ, Nieuwenhuis EE, Blumberg RS and Strober W. Oxazolone colitis, a Th2 colitis model resembling ulcerative colitis, is mediated by IL-13-producing NK-T cells. Immunity. 2002; 17(5): 629-38.

56. Tahan $\mathrm{G}$, Gramignoli $\mathrm{R}$, Marongiu $\mathrm{F}$, Aktolga S, Cetinkaya A, Tahan V and et al. Melatonin expresses powerful antiinflammatory and antioxidant activities resulting in complete improvement of aceticacid-induced colitis in rats. Dig Dis. Sci. 2011; 56(3): 715-20.

How to cite this article: Alimahdi $\mathrm{F}$, Shahrokhi N, Khaksari Hadad M, Asadikaram GhR, Abolhasani M. Effect of shilajit on the levels of pro-inflammatory and anti inflammatory cytokines in ulcerative colitis induced by acetic acid in male rats. Journal of Medicinal Plants 2020; 19(75): 78-91. doi: 10.29252/jmp.19.75.78 
Research Article

\title{
Effect of shilajit on the levels of pro-inflammatory and anti inflammatory cytokines in ulcerative colitis induced by acetic acid in male rats
}

\author{
Fatemeh Alimahdi', Nader Shahrokhi2,", Mohammad Khaksari Hadad ${ }^{2}$, Gholamerza \\ Asadikaram $^{3}$, Moslem Abolhasani ${ }^{4}$ \\ ${ }^{1}$ Kerman University of Medical Sciences, Kerman, Iran \\ ${ }^{2}$ Physiology Research Center, Institute of Basic and Clinical Physiology Sciences, Kerman University of \\ Medical Sciences, Kerman, Iran \\ ${ }^{3}$ Endocrinology and Metabolism Research Center, Institute of Basic and Clinical Physiology Sciences, \\ University of Medical Sciences, Kerman, Iran \\ ${ }^{4}$ Department of Biochemistry, Faculty of Medicine, Kerman University of Medical Sciences, Kerman, Iran
}

\begin{tabular}{|c|c|}
\hline ARTICLE INFO & ABSTRACT \\
\hline $\begin{array}{l}\text { Keywords: } \\
\text { Asphaltum } \\
\text { Cytokine } \\
\text { Shilajit } \\
\text { Sulfasalazin } \\
\text { Ulcerative colitis }\end{array}$ & $\begin{array}{l}\text { Background: The levels of IL-13, IL- } 4 \text {, IL-1B, TNF- } \alpha \text { and IL-10 alter in the colon } \\
\text { of people with ulcerative colitis. previous studies, it was found that shilajit } \\
\text { (asphaltum) was effective in the improvement of ulcerative colitis.we guessed that } \\
\text { the shilajit has been able to improve the ulcerative colitis by affecting the amount } \\
\text { of cytokines. Objective: The aim of the present study was to investigate the effects } \\
\text { of shilajit on IL-13, IL- } 4 \text {, IL-1B, TNF- } \alpha \text { and IL-10 in ulcerative colitis. Methods: } \\
\text { In this experimental study, } 49 \text { white male rats were randomly divided into } 7 \text { groups } \\
\text { including sham groups, ulcerative colitis, Gavage vehicle, Gavage shilajit, } \\
\text { sulfasalazine, Intra Anal Vehicle, Intra Anal shilajit. To produce ulcerative colitis } \\
2 \text { cc acetic acid ( } 4 \% \text { ) was prescribed intra-rectal. } 4 \text { days after the induction of } \\
\text { colitis, it was given } 4 \text { days: shilajit } 250 \text { mg / kg was used as a gavage or intra anal. } \\
\text { Sulfasalazine was dosed at } 250 \text { mg / kg in the form of gavage. Results: The Gavage } \\
\text { shilajit group increased IL-10, IL-4and decreased IL-1 } \beta \text {, TNF- } \alpha \text { compared to } \\
\text { Gavage vehicle group. Shilajit has been able to close the levels of IL-4, IL-13, IL- } \\
\text { 10, TNF- } \alpha \text { to normal values of the sham group. Conclusion: Considering that the } \\
\text { weight ratio of intestinal rat to the body of rat in the shilajit groups was lower than } \\
\text { that of the sulfasalazine group, it can be shown that shilajit has been able to more } \\
\text { reduce inflammation by making a more suitable change in cytokines in comparison } \\
\text { with sulfasalazine. }\end{array}$ \\
\hline
\end{tabular}

Abbreviations: UC, Ulcerative colitis; IBD, Inflammatory bowel disease.

* Corresponding author: nshahrokhisa@yahoo.com, nshahrokhi@kmu.ac.ir

doi: $10.29252 / \mathrm{jmp} .19 .75 .78$

Received 25 November 2018; Received in revised form 27 July 2019; Accepted 6 August 2019

(C) 2020. Open access. This article is distributed under the terms of the Creative Commons Attribution-NonCommercial 4.0 International License (https://creativecommons.org/licenses/by-nc/4.0/) 